\title{
Percepção de Usuárias do Sistema Único de Saúde Brasileiro Sobre o Plano de Parto
}

\author{
Users' Perception of the Brazilian Unified Health System About Birth Plan
}

\section{RESUMO}

Objetivo: Conhecer a percepção de usuárias do Sistema Único de Saúde brasileiro sobre o plano de parto. Metodologia: Trata-se de uma pesquisa qualitativa de caráter exploratório e descritivo. Foram entrevistadas puérperas, que realizaram o pré-natal e o parto no serviço público de saúde, na Cidade de Vitória de Santo Antão, Pernambuco, Brasil. Utilizou-se o critério de saturação teórica para dimensionar a amostra e verificar, objetivamente, o esgotamento do conteúdo para análise. Os resultados obtidos nas entrevistas foram analisados segundo a técnica de análise de conteúdo temática proposta por Bardin. Resultados: Emergiram três categorias de análise: percepção sobre o plano de parto; o impacto do plano de parto na maternidade; vivências do parto. $O$ incentivo à construção do plano de parto ainda é deficiente nas consultas individuais de pré-natal, no entanto, nos espaços coletivos de rodas de gestantes, diante da atuação multiprofissional, a sua divulgação vem se fortalecendo. Quanto à assistência hospitalar, foi possível perceber, nas falas das mulheres, a resistência dos profissionais em legitimar o plano de parto. Conclusões: Percebeu-se, nas falas das usuárias, o plano de parto como instrumento essencial para a construção de suas experiências na gestação e no momento do parto. As vivências relativas ao parto foram percebidas como satisfatórias, mesmo o plano de parto não sendo reconhecido pela equipe de profissionais, como um instrumento legal e de direito da gestante. Por outro lado, identificou-se, a partir dos discursos relativos ao momento do parto, a prática de intervenções não baseadas nas evidências científicas.

\section{DESCRITORES}

Saúde da Mulher. Parto Humanizado. Sistema Único de Saúde.

\begin{abstract}
Objective: To know the users' perception of the Brazilian Unified Health System about birth plan. Methodology: This is a qualitative, exploratory, and descriptive research. Women who recently gave birth and performed prenatal care and childbirth at the public health service in the city of Vitória de Santo Antão, Pernambuco, Brazil, were interviewed. The results obtained from the interviews were analyzed according to the thematic content analysis technique. Results: Three categories of analysis emerged: perceptions about the birth plan; the impact of the birth plan in the maternity hospital; childbirth experiences. The incentive to make the Childbirth Plan is still deficient in individual prenatal consultations, however, in collective spaces such as pregnant Women 'rounds of conversation', given the multiprofessional acting, its dissemination has been strengthening. As for hospital assistance, it was possible to perceive in the women's statements, the professionals' resistance to legitimize the Birth Plan. Conclusion: In the users' statements, the Birth Plan was perceived as an essential tool for constructing their experiences during pregnancy and at the moment of delivery. Most childbirth experiences were satisfactory, even though the Birth Plan was not recognized by the team of professionals as a legal instrument and a legal right of the pregnant woman. On the other hand, from the speeches related to the moment of delivery, the practice of interventions not based on scientific evidence was identified.
\end{abstract}

\section{DESCRIPTORS}

Women's Health. Humanizing Birth. Unified Health System.

${ }_{1}^{1}$ Psicóloga, Mestranda pelo Programa de Pós-Graduação em Psicologia - UFPE, Especialista em Atenção à Saúde - PRMIAS UFPE/ CAV. Paudalho - Pernambuco, Brasil.

${ }^{2}$ Enfermeira, Doutora em Enfermagem. Professora da Universidade Federal da Paraíba. João Pessoa - Paraíba, Brasil.

${ }^{3}$ Enfermeira, Doutoranda pelo Programa Associado de Pós-Graduação em Enfermagem da UPE/UFPB. Recife - Pernambuco, Brasil. 
A assistência ao parto e nascimento sofreu diversas modificações, passando de um evento fisiológico, essencialmente familiar e feminino, conduzido por parteiras da comunidade para um acontecimento hospitalar e medicalizado ${ }^{1}$. O modelo obstétrico hegemônico estabelecido passou a olhar para a mulher como uma máquina defeituosa que necessitava de intervenções, tirando-lhe a autonomia sobre o seu processo de parir e, aos poucos, fazendo-a desacreditar cada vez mais no seu corpo $^{2}$. Nesse sentido, as mulheres foram deixando de ter espaço em um campo que era essencialmente delas, desapropriadas de seus saberes, perdendo consequentemente seu protagonismo ${ }^{3}$.

O processo de institucionalização do parto fez com que esse momento se tornasse, em muitos casos, um evento estressante para a mulher, que perde a ligação com o espaço familiar, que Ihe trazia segurança e acolhimento, por um ambiente hostil, no qual é cuidada por pessoas desconhecidas levando a perda de um momento tão exclusivo e especial na sua vida ${ }^{4}$. Com o objetivo de incentivar as práticas baseadas em evidências científicas, o Ministério da Saúde (MS) ${ }^{5}$ e a Organização Mundial da Saúde (OMS) ${ }^{6}$ recomendam orientações que visam estimular as mulheres a participarem ativamente das decisões sobre o processo de gestação, parto e puerpério ${ }^{7}$.

Entre as boas práticas obstétricas, destaca-se o Plano de parto que se trata de um documento em que as gestantes podem expressar antecipadamente suas escolhas referentes ao cuidado que gostariam de receber durante o trabalho de parto, parto, pós-parto imediato e os primeiros cuidados ao recém-nascido, evitando intervenções desnecessárias e indesejadas e incentivando sua autonomia no processo de escolha ${ }^{8}$. O Plano de parto configura-se como um importante instrumento para a concretização da assistência obstétrica humanizada. Observase que o incentivo ou não da construção desse instrumento na atenção primária da saúde e o cumprimento do mesmo nas maternidades pode influenciar diretamente na experiência de parto das mulheres ${ }^{7}$.

Percebe-se que os profissionais de saúde exercem um papel relevante na concretização do plano de parto da mulher, uma vez que precisam tornar essa ferramenta acessível e legítima, promovendo também o acesso às informações seguras e respeitando as escolhas da mulher e de sua família.

Portanto, o Plano de parto apresentase como potencial ferramenta de combate à violência obstétrica e incentiva à humanização na atenção às parturientes, puérperas e recém-nascidos. A partir desse contexto, questiona-se: As usuárias do Sistema Único de Saúde (SUS) têm sido incentivadas a construir o seu Plano de parto durante do pré-natal?

Acredita-se que as mudanças no cenário da assistência obstétrica brasileira, parte da percepção de mulheres sobre a necessidade de demandar assistência segura e que isso é capaz de provocar rupturas no atual modelo obstétrico. Assim, estudos qualitativos se fazem necessários para elucidar as vozes de mulheres no cenário da assistência no processo de parto e nascimento. Posto isto, esse estudo objetivou conhecer a percepção de usuárias do Sistema Único de Saúde sobre o Plano de parto. 


\section{METODOLOGIA}

Trata-se de uma pesquisa qualitativa, de caráter exploratório e descritiva, realizada no território de abrangência da Unidade básica de saúde (UBS) do bairro CAIC, localizada na Cidade de Vitória de Santo Antão-PE. A escolha por este lugar como campo de pesquisa foi motivada pelo fato de existir o Projeto de Extensão "Ciranda Materna: gestar, parir e cuidar", do Centro Acadêmico de Vitória de Santo Antão, Campus da Universidade Federal de Pernambuco, localizado nesse município, o qual oferece cursos na área da saúde: Enfermagem, Saúde Coletiva, Nutrição, Educação Física e Ciências Biológicas. O projeto realiza rodas de conversas com gestantes com temas referentes à gestação, ao parto e ao puerpério. Foram incluídas puérperas maiores de 18 anos, primíparas ou multíparas, com acompanhamento pré-natal e parto em serviço público de saúde e que tivesse participado de, pelo menos, uma roda de conversa do projeto de extensão. Foram excluídas mulheres com transtornos mentais ou déficit cognitivo, comprovado por meio de laudo médico.

O recrutamento das puérperas ocorreu por meio de contato telefônico, a partir da lista de participantes que as organizadoras do projeto de extensão realizavam em cada encontro promovido na UBS. As entrevistas foram realizadas no período de dezembro de 2019 a janeiro de 2020.

Para coleta de material empírico, realizou-se entrevista por meio de roteiro semiestruturado com cinco perguntas norteadoras para o diálogo com as participantes: O que você conhece sobre
Plano de parto? Como a construção do Plano de parto foi incentivada no seu pré-natal? Como foi a experiência do seu parto? Você sentiu que foi respeitada em suas decisões? Caso tenha feito o Plano de parto, como a equipe o recebeu? Além dessas perguntas principais, perguntas secundárias foram realizadas no intuito de aprofundar melhor o que era trazido pelas entrevistadas. Para tanto, utilizou-se um aparelho celular para a gravação. As entrevistas foram realizadas na unidade de saúde, em sala reservada, resguardando a privacidade das participantes, com tempo médio de 40 minutos.

Utilizou-se critério de saturação teórica para dimensionar a amostra e verificar objetivamente esgotamento do conteúdo para análise. Para a confirmação da saturação teórica foi utilizado o método colorimétrico ${ }^{9}$, seguindo os seguintes passos: 1. Registro dos dados brutos: transcrição na íntegra das entrevistas; 2 . Imersão dos dados: leitura flutuante do texto de transcrição; 3 . Agrupamento temático: a partir das unidades de significação identificadas, realizou-se o agrupamento em categorias por meio da codificação colorimétrica; 4. Organização dos temas em um quadro: essa organização possibilitou identificar a regularidade dos achados nas entrevistas e dividi-las por temas (Quadro 1). Com a aplicação do método colorimétrico as respostas relacionadas ao que conhecem sobre o Plano de parto foram identificadas em azul, grupos de gestantes como espaço potencializador para o incentivo à construção do plano de parto de verde, empoderamento feminino em roxo, não legitimação do Plano de parto em laranja, violência obstétrica em amarelo e experiência 
satisfatória sobre o parto em vermelho. Sendo assim, percebeu-se que na quarta entrevista os conteúdos trazidos já se repetiam. Desta forma, seguiu-se a recomendação teórica ${ }^{9}$ foram realizadas mais duas entrevistas, relativas à um terço para confirmação da saturação.

Os resultados obtidos nas entrevistas foram analisados segundo a técnica de análise de conteúdo temática ou categorial proposta por $\operatorname{Bardin}^{10}$, seguindo a pré-análise, a exploração do material e a análise dos dados.

A pré-análise configurou-se na fase de organização do material empírico. As entrevistas foram transcritas a medida que foram sendo realizadas, constituindo o corpo da pesquisa. Logo após, foi realizada a leitura exaustiva do material, para esgotar a totalidade da comunicação e iniciado o processo de categorização. Na segunda fase, a exploração do material, as categorias de análise foram definidas. O material colhido foi dividido, relacionando-os com os objetivos propostos pela pesquisa. Na terceira fase do processo, realizou-se a inferência e interpretação dos dados.

Este estudo foi aprovado pelo Comitê de Ética em Pesquisa do Centro de Ciências da Saúde (CCS) da Universidade Federal de Pernambuco (UFPE) sob o Parecer de número 3.269.885 e CAAE: 10767619.2.0000.5208, atendendo às considerações éticas envolvidas na Resolução n . 466/12 e 510/16 do Conselho Nacional de Saúde (CNS).

Quadro 1. Entrevista de uma puérpera após a aplicação do método colorimétrico e agrupamento dos temas

\begin{tabular}{|c|c|c|}
\hline Pesquisadora & Entrevistada & Tema \\
\hline $\begin{array}{l}\text { O que você conhece sobre } \\
\text { Plano de Parto? }\end{array}$ & $\begin{array}{l}\text { "É onde mostra todos os direitos que a gestante } \\
\text { tem quando chegar no hospital." }\end{array}$ & $\begin{array}{l}\text { O que conhecem } \\
\text { sobre Plano de } \\
\text { Parto }\end{array}$ \\
\hline $\begin{array}{l}\text { Como a construção do } \\
\text { Plano de Parto foi } \\
\text { incentivada no seu Pré- } \\
\text { Natal? }\end{array}$ & $\begin{array}{c}\text { "Nas rodas de gestante nos mostraram e nos } \\
\text { deram um papel, foi um grupo de enfermeiras que } \\
\text { vieram participar e realizar algumas consultas de } \\
\text { pré-natal, elas me entregaram e me explicaram } \\
\text { tudinho." }\end{array}$ & $\begin{array}{c}\text { Grupos de } \\
\text { gestantes como } \\
\text { espaço } \\
\text { potencializador } \\
\text { para o incentivo à } \\
\text { construção do } \\
\text { plano de parto } \\
\end{array}$ \\
\hline $\begin{array}{l}\text { Como você percebe que o } \\
\text { Plano de Parto te ajudou } \\
\text { no processo de acesso a } \\
\text { informações importantes } \\
\text { sobre o parto? }\end{array}$ & $\begin{array}{c}\text { "Eu li muita coisa, sabe? quando eu tava grávida, } \\
\text { até essa questão do mecônio (...) Eu li até sobre } \\
\text { a indução, eu já conhecia um pouco." }\end{array}$ & $\begin{array}{l}\text { Empoderamento } \\
\text { feminino }\end{array}$ \\
\hline $\begin{array}{l}\text { Como a equipe recebeu } \\
\text { seu Plano de Parto? }\end{array}$ & $\begin{array}{c}\text { "As Enfermeiras disseram logo: 'olhe, não adianta } \\
\text { não, os médicos não respeitam não, aqui o doutor } \\
\text { sabe as coisas que tem que fazer e cada um faz } \\
\text { o que quer'." }\end{array}$ & $\begin{array}{l}\text { Não legitimação } \\
\text { do Plano de Parto }\end{array}$ \\
\hline $\begin{array}{l}\text { Você sente que foi } \\
\text { respeitada em suas } \\
\text { decisões? }\end{array}$ & $\begin{array}{c}\text { "Não fui respeitada porque eu queria muito que o } \\
\text { pai dele tivesse visto isso foi a principal coisa, } \\
\text { eles só respeitam quando é parto normal e olhe } \\
\text { lá." }\end{array}$ & $\begin{array}{l}\text { Violência } \\
\text { Obstétrica }\end{array}$ \\
\hline
\end{tabular}




\section{RESULTADOS}

Participaram seis mulheres com idade entre 25 a 35 anos, duas se afirmaram casadas e as quatro demais consideravam viver em união estável. Todas possuíam ensino médio completo e renda familiar entre 1 a 2 salários mínimos. Duas mulheres se autodeclararam como de raça/cor branca e quatro se autodeclararam como pardas.
Realizaram uma média de 8 consultas de acompanhamento pré-natal e participaram entre 1 a 3 rodas de conversas durante a gestação. Das entrevistadas, metade era primíparas. Cinco vivenciaram o trabalho de parto de maneira espontânea e uma mulher necessitou induzir o parto devido à idade gestacional ultrapassar às 41 semanas. Quatro tiveram parto vaginal e duas passaram por cesariana intraparto.

Tabela 1. Categorização do material coletado

\begin{tabular}{|c|c|c|}
\hline Unidades de significação & $\begin{array}{c}\text { Categoria } \\
\text { Intermediária }\end{array}$ & Categoria Final \\
\hline Plano de Parto como um documento de validade legal & \multirow{3}{*}{$\begin{array}{l}\text { O que conhecem } \\
\text { sobre Plano de Parto }\end{array}$} & \multirow{9}{*}{$\begin{array}{l}\text { Percepção sobre o } \\
\text { Plano de Parto }\end{array}$} \\
\hline Plano de Parto como garantidor de direitos & & \\
\hline O Plano de Parto permite mais autonomia à gestante & & \\
\hline $\begin{array}{l}\text { Maior incentivo na construção do Plano de Parto nos } \\
\text { espaços coletivos de cuidado, em detrimento das } \\
\text { consultas individuais }\end{array}$ & \multirow{3}{*}{$\begin{array}{l}\text { Grupos de gestantes } \\
\text { como espaço } \\
\text { potencializador para o } \\
\text { incentivo à construção } \\
\text { do Plano de Parto }\end{array}$} & \\
\hline $\begin{array}{l}\text { Rodas de gestantes como espaço de trocas de } \\
\text { experiências }\end{array}$ & & \\
\hline $\begin{array}{l}\text { Rodas de gestantes como espaço de propagação de } \\
\text { informações seguras baseadas nas evidências } \\
\text { científicas }\end{array}$ & & \\
\hline Desconstrução de mitos e medos sobre o parto & \multirow{3}{*}{$\begin{array}{l}\text { Empoderamento } \\
\text { feminino }\end{array}$} & \\
\hline Maior segurança no trabalho de parto & & \\
\hline Maior reconhecimento sobre direitos & & \\
\hline Recusa do Plano de Parto pela equipe de assistência & \multirow{3}{*}{$\begin{array}{l}\text { Não legitimação do } \\
\text { Plano de Parto }\end{array}$} & \multirow{3}{*}{$\begin{array}{l}\text { O impacto do } \\
\text { Plano de Parto na } \\
\text { Maternidade }\end{array}$} \\
\hline $\begin{array}{c}\text { Maternidade não incentiva a apresentação do Plano } \\
\text { de Parto }\end{array}$ & & \\
\hline $\begin{array}{l}\text { O receio em apresentar o Plano de Parto e provocar } \\
\text { questionamentos por parte dos profissionais }\end{array}$ & & \\
\hline Descumprimento da lei do acompanhante & \multirow{3}{*}{ Violência obstétrica } & \multirow{5}{*}{ Vivências do Parto } \\
\hline Burocratização do atendimento & & \\
\hline Violência verbal & & \\
\hline $\begin{array}{l}\text { Boa assistência apesar do não reconhecimento do } \\
\text { Plano de Parto }\end{array}$ & \multirow{2}{*}{$\begin{array}{l}\text { Experiência } \\
\text { satisfatória sobre o } \\
\text { parto }\end{array}$} & \\
\hline $\begin{array}{l}\text { Relativização da qualidade da assistência baseado } \\
\text { nos plantôes das equipes }\end{array}$ & & \\
\hline
\end{tabular}


Todas relataram ter tido acompanhante durante o trabalho de parto, sendo que uma afirmou que no momento da cesárea o acompanhante foi impedido de permanecer na sala pela equipe do hospital. Os partos foram assistidos por profissionais médicas(os). Nenhuma das entrevistadas teve acompanhamento de doula. As falas foram categorizadas em unidades de significação. Em seguida, foram agrupadas em categorias intermediárias a partir da semelhança de conteúdo e, por fim, agrupadas nas categorias finais. A Tabela 1 apresenta a categorização do material coletado.

Categoria 1. Percepção sobre o Plano de Parto

Esta categoria exibe as percepções das mulheres sobre o Plano de parto, a sua finalidade e a forma como esse instrumento Ihes foi apresentado. Evidencia-se nas falas a importância das rodas de conversas durante o acompanhamento pré-natal como espaço de fortalecimento e incentivo da construção do Plano de parto e promoção do empoderamento sobre o processo de parir.

Então, o plano de parto que conheci de fato é um documento, né? Algumas opções para gestante em termos de conhecimento, que às vezes muitas gestantes não tem, né?(...) São situações que poderiam ocorrer lá e ela tem a opção deixar já com antecedência, sinalizado como ela prefere. (Entrevistada 1)

Eu conheço que é um documento onde a gente expõe nossos desejos, o que é que a gente quer que aconteça durante o parto, para que os médicos não tomem alguma atitude que não seja o que a gente desejaria, e também depois que o bebê nasce o que é que a gente quer que aconteça com ele, Que ele fique com a gente, não saia de perto, alguns procedimentos que devem ser feitos tanto no parto, quanto com bebê. (Entrevistada 5)

É como se fosse um recurso que ajuda a gestante a ter mais autonomia e demonstrar seu interesse na hora do parto. (...) A gestação é um processo longo e que você com plano de parto você tem um tempo para pensar, você tem o tempo de analisar, inclusive algumas pessoas que lendo acaba tendo conhecimento de coisas que não tinha antes.. (Entrevistada 4)

Quando questionadas sobre o incentivo da elaboração do Plano de parto nas consultas de pré-natal, o discurso difere entre aquelas que tiveram conhecimento desse instrumento em uma consulta de pré-natal individual e as que não tiveram acesso. No entanto, aparece a unanimidade sobre a sua divulgação nas rodas de gestantes realizadas na unidade de saúde.

Foi na roda de gestantes mesmo. Nas consultas a enfermeira já falava, mas na roda de gestantes foi mais incentivado, foi mostrado como a gente poderia se comportar nas contrações, até na amamentação, no pós-parto. (Entrevistada 6) 
Foram mais nas rodas de gestante(...) Que foram onde elas foram mostrando o que a gente faria. No meu pré-natal foi onde eu tive contato com plano de parto. Na caderneta de gestante também vinha falando sobre ele, mas de forma muito resumida. (Entrevistada 5)

Foi unânime o discurso de valorização das rodas de conversa durante o pré-natal enquanto espaço de potencial troca de experiência e de informações seguras, baseadas nas evidências científicas.

Há 6 anos atrás, eu não tive acompanhamento assim pelo SUS eu quis fazer as coisas pelo particular, então não tinha acompanhamento no postinho. (...) dessa vez eu me preparei mais, me programei mais. Fui muito bem mais orientada, pude cuidar do meu corpo melhor, da minha alimentação. As rodas de gestantes foram muito importantes, falar sobre alimentação, sobre os exercícios, exercícios para o parto. (Entrevistada 1)

As rodas foram muito importantes, porque tirou dúvidas, né? Eu tinha muito medo do parto, mas acho que eu perdi um pouco nas rodas, recebi muito apoio, foi muito boa a diferença das rodas por conta disso, de tirar as dúvidas e ver as outras pessoas. $E$ saber que o parto não é esse bicho todinho que todo mundo prega, né? (Entrevistada 2)
Percebeu-se nas falas, a conexão entre a construção do Plano de parto e o processo (des)construção do conhecimento e, consequentemente, o empoderamento sobre que decisões tomar para o momento do parto.

Como hoje eu tenho conhecimento, depois do plano de parto, depois dos encontros, eu não passei o que passei com a minha primeira filha. (...) E aí nesse segundo parto eu já fui preparada, bem mais munida de conhecimento, do que eu podia e do que eu não podia, até onde até onde ia meu direito. (Entrevistada 1)

(...) pesquisei muito e aí no hospital eu já tava com uma postura, que se elas quisessem fazer algo eu dizia: "não, mas eu li sobre isso", eu sempre ficava falando: "eu li sobre isso", mostrei que eu não era uma pessoa leiga no assunto, então foi isso, eu me empoderei do assunto. (Entrevistada 3)

Categoria 2. O impacto do Plano de parto na maternidade

Nesta categoria apresentam-se as experiências das gestantes a partir da entrega do Plano de parto no serviço de saúde público, quando as mesmas deram entrada para parir. Vale ressaltar, que as falas se referem à mesma maternidade, o que possivelmente muda de uma para outra são as equipes que prestaram assistência obstétrica.

Disseram logo: 'olhe, não adianta não, os médicos não respeitam não, aqui o doutor sabe as coisas que tem que 
fazer e cada um faz o que quer. Não tem isso não.' $E$ aí eu ia fazer o quê? Se por mais que a gente insiste, insiste em falar, até lá em cima, eu também falei, mas nada. (Entrevistada 2)

Assim que fui pra triagem eu já entreguei minha pasta com todos os documentos e mandei colocar o Plano de Parto logo no prontuário, pra que mesmo quando houvesse uma mudança de turno, de plantão, o prontuário estar lá. (...)Em nenhum momento eu vi elas pegando no meu plano de parto, eu acho que elas viram, né, que tava lá no prontuário, mas não leram não. (Entrevistada 4)

Apenas uma das entrevistadas acredita que seu Plano de parto foi seguido e respeitado.

Meu Plano de Parto foi seguido (...) Eu tive sorte do plantão ser maravilhoso, eu tenho conhecimento e sei que foi realizado dentro do plano de parto natural. (Entrevistada 6)

\section{Categoria 3. Vivências do Parto}

Observou-se nessa categoria que, apesar do não reconhecimento do Plano de parto na maternidade, a maioria das mulheres acredita terem sido respeitadas em suas decisões mesmo vivenciando algumas intervenções obstétricas não recomendadas de forma rotineira, tais como toque vaginal excessivo e amniotomia de rotina.

Eu fui muito respeitada, inclusive, as outras mulheres que estavam lá também no quarto comigo. Com relação ao atendimento, em relação as minhas condições, foi tudo dentro do meu tempo mesmo. Eu não fui forçada a ser mais depressa, não fui para o lugar que eu não queria ir, entendeu? Não fui agredida. (Entrevistada 1)

Eu quis ter no [nome do hospital] por causa disso, porque no primeiro parto todas as minhas decisões foram respeitadas e fizeram de tudo pra que eu não sofresse tanto, então pra mim tanto, a primeira experiência como essa agora, eu fui super bem atendida. Eu sei que depende muito do plantão. (Entrevistada 6)

No entanto, algumas experiências não foram satisfatórias, caracterizando o parto como um evento violento.

Eu sofri, viu? Foi agoniado. Não fui respeitada porque eu queria muito que o pai dele tivesse visto isso foi a principal coisa, eles só respeitam quando é parto normal e olhe lá. $E$ aí na cesárea? Por que eles não deixam na cesárea também? Acho que eles têm medo de acontecer alguma coisa e aquela pessoa ser testemunha de algo (...) Se a pessoa leva um acompanhante a gente quer que aquela pessoa veja, né? (Entrevistada 2)

(...) Teve uma hora que queriam colocar alguma coisa na minha uretra, porque estavam dizendo que eu tinha que fazer xixi, aí me perguntaram se 
eu queria e eu não deixei, aí ela ficou insistindo, insistindo, e eu dizendo que não, até que ela ia colocar sem eu deixar, até que chegou outra enfermeira do meu lado, que era residente e disse pra mim: "não deixe não", ela foi mais acolhedora do que a própria enfermeira do plantão. (Entrevistada 3)

\section{DISCUSSÃO}

A ferramenta do Plano de parto fortalece o vínculo que se estabelece entre a mulher e o profissional de saúde que presta assistência e orienta o cuidado ao longo de todo o ciclo gravídico-puerperal, fornecendo informações seguras, atuais e respeitando as escolhas da mesma ${ }^{11}$. Um estudo ${ }^{1}$ realizado no Canadá em 2013, com 122 gestantes e puérperas e 110 profissionais de saúde, apontou que $53 \%$ das mulheres e $57 \%$ dos profissionais de saúde afirmaram que o Plano de parto age como uma ferramenta de comunicação entre a gestante, o seu acompanhante e os profissionais que irão prestar a assistência, permitindo o entendimento e o reconhecimento das decisões da mulher sobre o parto.

O Plano de parto se enquadra dentre as tecnologias não invasivas de cuidado obstétrico, pelo fato de trazer conforto, confiança, estimular o pensamento crítico e o autoconhecimento sobre o corpo e a capacidade de parir 8 . No entanto, observouse a partir das entrevistas que existe pouco incentivo nas consultas de pré-natal quanto ao uso dessa ferramenta. Estudo de Silva et al. ${ }^{12}$, de caráter quantitativo e descritivo, realizado em Belo Horizonte - MG no ano de 2014, entrevistou 106 gestantes que realizaram pré-natal na atenção básica, evidenciando que $74 \%$ das entrevistadas apesar de terem a caderneta da gestante, a qual consta um modelo de Plano de parto a ser preenchido, não receberam essa informação durante as consultas.

Este presente estudo apontou que o nível de conhecimento sobre o Plano de parto é pequeno tanto para as gestantes quanto para os profissionais de saúde. Mouta et al. ${ }^{8}$, em sua pesquisa realizada em 2017 , no Município do Rio de Janeiro, com onze mulheres sobre o uso dessa ferramenta apontou que apenas uma delas conhecia o que era o Plano de parto, as demais relatam que só vieram ter conhecimento sobre esse instrumento apenas na Casa de Parto. Assim, apesar de ser reconhecida como umas das técnicas que devem ser estimuladas na gestação, preconizadas pela $\mathrm{OMS}^{6}$, evidencia-se que a prática deste instrumento é pouco estimulada nos serviços públicos de assistência obstétrica ${ }^{13}$.

Em contrapartida, as rodas de conversas promovidas durante o acompanhamento prénatal tornam-se espaços coletivos de troca de experiência, saberes científicos e populares. Nesse contexto, trabalhar com grupos na atenção básica proporciona uma forma de compreensão e de percepção da cultura, formas de relações, educação e o fazer saúde de uma determinada comunidade com uma riqueza de detalhes que o atendimento individual, por vezes, não alcança, além de ir na contramão do modelo hegemônico biomédico e curativista ${ }^{14}$.

Rego et al. ${ }^{14}$ em sua pesquisa realizada entre os anos de 2016 e 2017, no Município do Rio de Janeiro-RJ, com 
21 participantes de grupos realizados na atenção básica, evidenciou que as atividades coletivas contribuem para a transformação do modelo biomédico de atenção e que as práticas de saúde desenvolvidas, a partir das necessidades do território, favorecem a valorização cultural daquele local e agregam de forma educativa e psicoafetiva na vida dos sujeitos.

No trabalho em grupo com mulheres gestantes, esses aspectos estão presentes de maneira marcante, uma vez que sempre são trazidas construções sociais que envolvem o tema da gestação, do parto e do puerpério. Muitos medos, principalmente relacionados ao tema do parto, são construídos socialmente e carregados de experiências negativas, frutos de uma violência obstétrica vivenciada por gerações e dos mitos que envolvem a temática ${ }^{15}$.

No ano de 2017, Alves et al. ${ }^{15}$ realizou um estudo com 21 gestantes de alto risco internadas em uma maternidade em FortalezaCE, a partir do método de grupos focais, analisou-se os discursos das participantes em que os grupos promoveram a partilha de experiência, o fortalecimento de vínculo entre gestantes e profissionais da assistência, o aprendizado e a reflexão sobre o processo gravídico-puerperal, reduzindo a ansiedade e contribuindo para a tomada de decisões e consequente empoderamento.

Este estudo confirma o que outras pesquisas $^{14,17}$ apontam sobre a construção do Plano de parto, estimulado em rodas de gestantes, que possibilita maior autonomia e conhecimento por parte das mulheres para fazerem suas próprias reflexões e escolhas, a partir da apropriação de conceitos baseados nas evidências científicas. Isso faz com que as mesmas cheguem de maneira mais confiante no momento do parto, de forma a questionar intervenções e negar procedimentos desnecessários embasada em informações seguras.

Um estudo realizado na Espanha ${ }^{18}$, entre os anos de 2009 a 2013, analisou 178 prontuários de gestantes que apresentaram Plano de parto na admissão da maternidade, no momento em que foram parir. Dentre os resultados encontrados, evidenciou-se que $3,4 \%$ das mulheres não tiveram seu Plano de parto seguido em nenhum dos pontos; para $27 \%$ das mulheres, apenas $25 \%$ do total de solicitações foram cumpridas; para 32,5\% a ferramenta foi seguida em $50 \%$; para $29,2 \%$ das mulheres, esta foi cumprida na sua maior parte $(75 \%)$ e o Plano de parto foi totalmente cumprido para apenas $7,9 \%$ das mulheres.

O baixo grau de aceitação do Plano de parto pelas equipes que prestam assistência, pode se dar a partir de diversos motivos. No entanto, dois podem ser destacados: o primeiro se refere ao desenrolar do parto, que pode tomar um rumo inesperado e exigir condutas que fujam das preferências adotadas pela parturiente. Por outro lado, pode ser gerada uma tensão entre as/os profissionais e a gestante, pelo fato do Plano de parto poder significar uma perda de autonomia profissional, significando uma barreira à assistência ${ }^{18}$.

Estudo $^{19}$ realizado em 2016, em maternidade localizada no Teresina-PI, analisou a percepção de puérperas sobre a violência obstétrica, tendo sido entrevistadas 20 mulheres, ficando evidenciada a desinformação acerca de seus direitos 
enquanto parturientes. A Fundação Perseu Abramo no ano de 2010 realizou uma grande pesquisa ${ }^{20}$, que entrevistou 2.365 mulheres de todo o território brasileiro e identificou que 1 a cada 4 mulheres já sofreram violência obstétrica, sendo as mais comuns, os gritos, a falta de analgesia e os procedimentos dolorosos sem consentimento ou informação.

No entanto, existem outros tipos, diretos ou sutis, que acabam não sendo reconhecidos como violência obstétrica pelas mulheres que as vivenciaram, o que reflete desconhecimento pela falta de acesso a informações seguras. Ter acesso à ferramenta de Plano de parto, por si só, não garante o conhecimento sobre quais boas práticas precisam acontecer no momento do parto. É preciso fortalecer a sua disseminação nos espaços coletivos de rodas de conversa e, sobretudo, nas consultas de pré-natal ${ }^{7}$.

Um estudo(11), realizado no biênio de 2011-2012, analisou 9.303 partos realizados em maternidade pública da Espanha. Deste total, 240 mulheres utilizaram o Plano de parto com resultado positivo e significativo comparado a mulheres que não apresentaram a ferramenta de Plano de parto. No estudo, a prática do contato pele a pele teve um aumento significativo ( $33 \%$ de um ano para o outro) comparado com mulheres que não apresentaram o Plano de parto, o clampeamento tardio do cordão umbilical apresentou aumento de 15,2\%. Outro dado importante apresentado foi a taxa de partos normais que aumentou de $73,8 \%$ para $81,66 \%$. Desse modo, acredita-se que o Plano de parto tem o potencial de desempenhar um papel integral na transmissão eficaz das preferências das mulheres facilitando decisões informadas e uma experiência satisfatória para as mulheres e também para os profissionais que prestam assistência ${ }^{1,17}$.

O presente estudo apresenta limitações quanto à abrangência dos resultados, uma vez que o recorte das percepções e vivências das participantes é de maneira local, focada nas experiências dos serviços públicos de um município. No entanto, os resultados encontrados corroboraram com outras pesquisas de maior amplitude, como aqui foram descritas. Faz-se urgente a mudança de paradigmas na assistência à gestante, desde o acompanhamento do prénatal, na atenção básica, até a assistência hospitalar no parto e pós-parto imediato. Para tanto, a atuação dos profissionais deve promover autonomia, segurança e resgate do protagonismo da mulher em todo o ciclo gravídico-puerperal ${ }^{16}$.

\section{CONCLUSÕES}

O Plano de parto torna-se uma importante ferramenta que possibilita a autonomia e empoderamento das mulheres. Diante dessa perspectiva, as participantes o percebem como instrumento essencial para a construção de suas experiências na gestação e no momento do parto.

Com isso, acredita-se que o seu incentivo na atenção básica proporciona a ruptura de um modelo de assistência tecnocrático e intervencionista, visto que cada vez mais mulheres chegam à assistência hospitalar cientes dos seus direitos e sentemse mais seguras sobre o seu processo de parir. As experiências relativas ao parto foram satisfatórias em sua maioria, mesmo o Plano 
de parto não tendo sido reconhecido pela equipe de profissionais como um instrumento legal e de direito da gestante. Por outro lado, identificou-se, a partir dos discursos

\section{REFERÊNCIAS}

1. Aragon M, Chhoa E, Dayan R, Kluftinger A, Lohn Z, Buhler K. Perspectives of expectant women and health care providers on birth plans. J Obstet Gynaecol Can. 2013; 35(11):979-985

2. Maia M. Assistência à saúde e ao parto no Brasil [livro eletrônico]. Rio de Janeiro: Editora FIOCRUZ; 2010.

3. Vendrúsculo CT, Kruel CS. A História Do Parto: Do Domicílio Ao Hospital; Das Parteiras Ao Médico; De Sujeito A Objeto. Disciplinarum Scientia. 2015; 16(1):95-107.

4. Riscado LC, Jannotti CB, Barbosa RHS. A Decisão pela Via de Parto no Brasil: Temas e Tendências na Produção da Saúde Coletiva. Texto Contexto Enferm. 2016; 25(1):e3570014.

5. Brasil. Ministério da Saúde. Diretrizes nacionais de assistência ao parto normal. Brasília: Ministério da Saúde, 2017

6. WHO/OMS. Intrapartum care for a positive childbirth experience. 2018

7. Gomes RPC, Silva RS, Oliveira DCC, MANZO BF, Figueiredo B, Guimarães GL, Souza KV. Plano de Parto em Rodas de Conversa: Escolhas das Mulheres. REME - Rev Min Enferm. 2017; 21:e-1033.

8. Mouta RJO, Silva TMA, Melo PTS, Lopes NS, Moreira VA. Plano de parto como estratégia de empoderamento feminino. Rev Baiana Enferm. 2017; 31(4):e20275.

9. Nascimento LCN, Souza TV, Oliveira ICS, Morais JRM, Aguiar RCB, Silva LF. Saturação teórica em pesquisa qualitativa: relato de experiência na entrevista com escolares. Rev Bras Enferm. 2018; 71(1):228-33.

10. Bardin L. Tradução: Luís Antero Reto e Augusto Pinheiro. Análise de Conteúdo. 4ed. Lisboa: Edições 70, 2009.

11. Cortés MS, Barranco DA, Jordana MC, Roche MEM. Use and influence of Delivery and Birth Plans in the humanizing delivery process. Rev Latino-Am Enferm. 2015; 23(3): 520-526.

12. Silva WNS, Azevedo JAF, Holanda VR, Gomes ALV, Albuquerque GPM. Plano de parto como instrumento das boas práticas no parto e nascimento: revisão integrativa. Rev Baiana Enferm. 2019; 33:e32894. relativos ao momento do parto, a prática de intervenções não baseadas nas evidências científicas, que ainda são realizadas de maneira rotineira nos serviços de assistência obstétrica no SUS.

13. Silva SG, Silva EL, Souza KV, Oliveira DCC. Perfil de gestantes participantes de rodas de conversa sobre o plano de parto. Enfermagem Obstétrica. 2015; 2(1):9-14.

14. Rego LS, Figueiredo GO, Romano VF, Baião MR. As atividades de grupo na perspectiva dos sujeitos em uma Clínica da Família. Physis: Revista de Saúde Coletiva. 2019; 29(3): e290316.

15. Alves FLC, Castro EM, Souza FKR, Lira MCPS, Rodrigues FLS, Pereira LP. Grupo de gestantes de alto-risco como estratégia de educação em saúde. Rev Gaúcha Enferm. 2019; 40:e20180023.

16. Silva JC, Rodrigues MS. Boas práticas na assistência ao parto: implicações do plano de parto. Rev Bras Ciência e Vida. $2017 ; 5(4): 1-27$

17. Méndez FSF, Ferrer LTV, Muñoz MMN, Gómez JAR, Jaime AA. El empoderamiento de la gestante y su satisfacción durante el parto. Dilemata. 2018; (26):207-15.

18. Hidalgo-Lopezosa P, Hidalgo-Maestre $M$, Rodríguez-Borrego MA. Birth plan compliance and its relation to maternal and neonatal outcomes. Rev Latino-Am Enferm. 2017; 25:e2953.

19. Oliveira TR, Costa REOL, Monte NL, Veras JMMF, Sá MIMR Percepção das mulheres sobre violência obstétrica. Rev Enferm UFPE. 2017; 11(1):40-46.

20. Fundação Perseu Abramo [página em Internet]. Pesquisa Mulheres Brasileiras e Gênero nos Espaços Público e Privado. 2010.

\section{CORRESPONDÊNCIA}

Ana Rebeca Paulino Portela

Quinta Travessa Marechal

Deodoro da Fonseca, 39

Alto Bela Vista, Paudalho - PE.

E-mail: anarebeca.pportela@gmail.com 